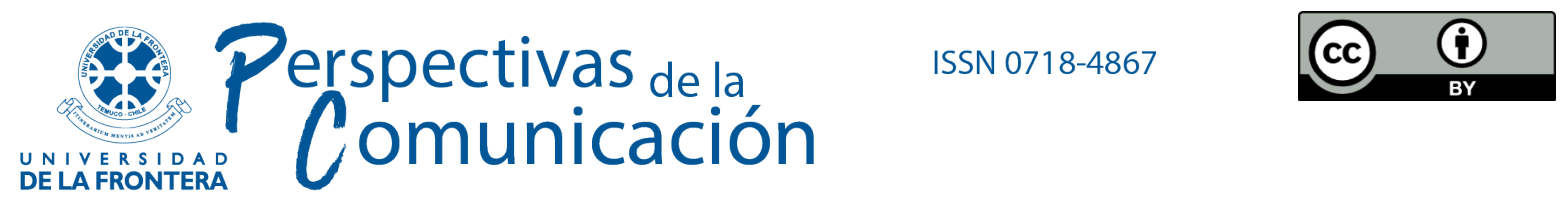

Artículo

\title{
INFORMACIÓN DURA-PÚBLICA Y BLANDA-PRIVADA PUBLICADA POR CANDIDATOS Y CANDIDATAS EN INSTAGRAM DURANTE LA CAMPAÑA ELECTORAL EN ARGENTINA 2019
}

DOI: POR ASIGNAR

Dra. Virginia García-Beaudoux

CONICET, Instituto de Investigacion Gino Germani, Universidad de Buenos Aires, Buenos Aires, Argentina copub@ub.edu.ar

ORCID iD: https://orcid.org/o0oo-0003-2428-8056

Dra. Ana Slimovich

CONICET, Instituto de Investigacion Gino Germani, Universidad de Buenos Aires, Buenos Aires, Argentina aslimovich@gmail.com

ORCID iD: https://orcid.org/o0oo-0002-7297-4942

Recibido el 2020-10-23

Revisado el 2021-05-03

Aceptado el 2021-05-04

Publicado el 2021-07-12

\section{Resumen}

En este artículo se presentan los resultados de una investigación que explora las características de las publicaciones efectuadas en Instagram por candidatos y candidatas a cargos electivos en Argentina durante la campaña para las elecciones 2019. Se analizó la proporción de información dura-pública e información blanda-privada o politainment que publicaron, y qué tipo de publicación recibió más likes. Los resultados indican la necesidad de redefinir las categorías analíticas "información dura" e "información blanda" tal como se las utiliza actualmente para estudiar este tipo de fenómenos de comunicación política.

Palabras clave: Instagram, elecciones, política, entretenimiento. 


\title{
HARD-PUBLIC INFORMATION AND SOFT-PRIVATE INFORMATION POSTED BY CANDIDATES ON INSTAGRAM DURING THE 2019 ARGENTINIAN ELECTORAL CAMPAIGN
}

\begin{abstract}
This paper presents the results of a research that explores the main features of Instagram publications of the candidates that participated in the electoral campaign that took place in Argentina in 2019. The proportion of hard-public information and soft-private information or politainment was analyzed, as well as which type of publications received more "likes". The results indicate the need to redefine the analytical categories hard information and soft information as they are currently used to study political communication phenomena.
\end{abstract}

Keywords: Instagram, elections, politics, entertainment. 


\section{Introducción}

La mediatización en tanto "secuencia de fenómenos mediáticos históricos que resultan de determinadas materializaciones de la semiosis, obtenidas por procedimientos técnicos" (Verón, 2013, p. 147) se inserta en el proceso de evolución de la especie.

La asociación entre fenómeno mediático y aceleración del tiempo evolutivo se confirma a lo largo de toda la historia del sapiens, como así también el carácter acumulativo del proceso; vale decir que la aceleración se acelera a medida que los fenómenos mediáticos se suceden (p. 176).

El proceso de mediatización de lo político se aceleró en el último cuarto del siglo XX y se vio favorecido, entre otros factores, por un proceso de desanclaje de las identidades partidarias y una mayor fluctuación en las preferencias de los votos de la ciudadanía (Hjarvard, 2008, 2014; Strömbäck, 2008; Strömbäck \& Esser, 2014; Verón, 2001).

La mediatización de la política en los medios tradicionales ha implicado históricamente un "entrelazamiento a menudo difícil de desanudar entre estrategia colectiva (relacionada con la formación política a la que el candidato representa) y estrategia individual (relacionada al mismo tiempo con rasgos de personalidad del candidato, pero también con sus ambiciones personales)" (Verón, 1998, p. 223). Esta mixtura cobra una dimensión especial frente al surgimiento y expansión de discursos políticos en las redes sociales, que en el caso de Argentina se generó en los inicios de la segunda década del siglo XXI.

Los políticos y políticas de Argentina abrieron sus cuentas personales en Facebook y Twitter entre 2009 y 2010. En este sentido, la primera campaña electoral que se desarrolló también en las redes sociales fue la que antecedió a la elección presidencial de 2011 (Slimovich, 2016). A partir de ese momento, se generó una predominancia de cuentas de candidatos y candidatas en las plataformas mediáticas por sobre las institucionales de las fuerzas políticas o partidos.

Con relación a Instagram, la mayoría de los políticos y políticas argentinas abrió una cuenta propia en dicha red social durante los últimos tres años. Por consiguiente, la elección presidencial de 2019 se constituye en uno de los primeros sufragios en los que también hay 
discursos de campaña en Instagram ${ }^{1}$. Este hecho nos condujo al planteo de dos interrogantes específicos: ¿qué características tienen las publicaciones realizadas por los candidatos y candidatas en 2019 ateniendo a la dimensión información dura-pública versus información blanda-privada-politainment? Y, considerando esa misma dimensión, ¿cuáles son las publicaciones que recibieron más likes por parte de los usuarios durante la campaña electoral? Estas preguntas han guiado nuestro trabajo

El objetivo de esta investigación es explorar las características de las publicaciones de los candidatos y candidatas en Instagram, durante la campaña electoral correspondiente a las elecciones generales de 2019 que tuvieron lugar en Argentina. Para ello, se analizarán los discursos de todos los candidatos y candidatas en la red social, durante el último mes de campaña electoral. Asimismo, se hará foco en los motivos temáticos utilizados en tres representantes del Frente de Todos: Alberto Fernández, Axel Kicillof y Cristina Fernández de Kirchner. Se apunta a indagar en los modos de los discursos teniendo en cuenta la diferenciación información dura-información blanda.

El trabajo se estructurará del siguiente modo. En la primera sección, se presentarán las consideraciones que sirven a modo de marco teórico de la investigación realizada. En segundo término, se desarrollará el herramental metodológico. En una tercera sección se realizará el análisis y, por último, la discusión de los resultados y las conclusiones.

\section{Consideraciones teóricas}

\subsection{Personalización de la política}

En la contemporaneidad estamos siendo testigos del establecimiento de nuevos fenómenos de relación entre el sistema de medios masivos y el sistema de redes sociales. Se conoce a

1 En 2017 se celebraron las elecciones de medio término en la Argentina y en relación a los diputados nacionales "Cambiemos se impuso en trece de veinticuatro distritos, mejorando notablemente su desempeño respecto de 2015” (Tagina, 2018: 43). Por su parte, Fernández de Kirchner fue elegida senadora y posicionada como principal líder de la oposición, no obstante, con disidencias con el resto del peronismo. La campaña presidencial de 2019 implicó un reacomodamiento en las dos fuerzas: por un lado, se constituyó el Frente de Todos, con Alberto Fernández como candidato a presidente y Cristina Fernández de Kirchner como candidata a vicepresidenta; y por otro, Juntos por el Cambio, liderado por Mauricio Macri, quien aspiraba a la reelección y Miguel Ángel Pichetto, como candidato a vicepresidente. 
esta etapa como "sociedad hipermediatizada" (Carlón, 2016). Las prácticas políticas no constituyen una excepción y se ven también influidas por estas nuevas condiciones de la circulación de los discursos. En esta etapa de la mediatización de lo político, diversos autores se han referido a la imbricación de la política en las redes sociales, a operaciones de digitalización de lo político, a las múltiples relaciones entre las lógicas mediáticas y las de las redes sociales en la construcción del discurso político, y a procesos de interacción entre gobernantes y gobernados sin que los periodistas actúen como intermediarios (Fernández, 2014 Mazzoleni \& Schulz, 1999; Slimovich, 2012, 2016, 2018b; Strömbäck, 2008; Strömbäck \& Esser, 2014; Verón, 2013).

El proceso de personalización y personalismo de la política que viene teniendo lugar desde hace décadas y al que han hecho referencia diversos académicos (Castells, 2009; Cheresky, 2006; D’Adamo \& García-Beaudoux, 2013; García-Beaudoux, D’Adamo \& Slavinsky, 2005; Manin, 1998), ha dado un nuevo giro con las redes sociales. Los candidatos tienden a aparecer con frecuencia como individuos que exhiben su intimidad y ofrecen su experiencia a los electores, más que como representantes de organizaciones partidarias. Los candidatos apelan al voto heurístico a través de recursos del orden del conmover y de la primera persona. La ciudadanía participa de este proceso dada su "atracción por conocer los detalles y anécdotas de los líderes políticos" (García-Beaudoux, D’Adamo \& Slavinsky, 2005, p. 60).

Proponemos que un modo de acceder a la observación de las características del fenómeno de la personalización en las redes sociales de los políticos y las políticas en la Argentina puede efectuarse a partir de la distinción entre publicaciones en las que enfatizan los aspectos duros, públicos o propiamente políticos de la información; y las publicaciones en las que, por el contrario, eligen hacer foco en aspectos blandos, privados o de entretenimiento político.

En la lectura científica en comunicación es frecuente encontrar trabajos que hacen referencia a las nociones de soft $y$ hard news (noticias blandas y duras). Sin embargo, no existe un consenso o definición unívoca en el modo en que investigadores y académicos definen esos términos, tanto en sus aspectos conceptuales como metodológicos. Tuchman (1972, 1973) sostiene que la distinción entre ambas categorías de noticias es la "sustancia". Propone que las noticias duras necesitan comentarios y análisis; mientras que las blandas involucran escándalos, chismes, farándula e historias de interés humano, con pocas ramificaciones más allá de lo inmediato. Patterson (2000) afirma que las noticias blandas 
contienen elementos sensacionalistas, hacen centro en personalidades famosas, o se refieren a eventos episódicos y desconectados de otras historias o tendencias sociales. LehmanWilzig y Seletzky (2010, p. 48) creen necesario sumar una tercera categoría intermedia de clasificación, y proponen denominarla noticias generales. Definen a las noticias blandas como informaciones livianas o picantes, tales como el cotilleo referido a las celebridades o las denominadas historias de interés humano; y a las noticias duras como novedades, hallazgos o descubrimientos del campo de la política, la economía, la sociedad, el medioambiente o la salud pública con ramificaciones e impacto en el ámbito público, nacional o internacional. Curran et al. (2009) definen las noticias duras como aquellas que informan sobre política, administración pública, economía, ciencia, tecnología y otros temas afines; mientras que las blandas como aquellas que refieren a celebridades, cuestiones de interés humano, deportes e historias centradas en el entretenimiento.

Un metanálisis realizado por Reinemann et al. (2011, p. 5), identifica cinco dimensiones que, de manera combinada o aislada, se emplean para definir las noticias blandas y duras: 1 . temas/eventos; 2. producción de las noticias; 3. frame; 4. estilo noticioso; 5. recepción de las noticias. Proponen la siguiente definición:

Cuanto más un ítem noticioso es políticamente relevante, cuanto más se reporte en un modo temático, se enfoque en las consecuencias sociales de los eventos, sea impersonal y no emocional en su estilo; más podrá ser considerado como noticia dura. Cuanto más un ítem noticioso no sea políticamente relevante, cuanto más sea reportado en un modo episódico, se enfoque en las consecuencias individuales de los eventos, sea personal y emocional en su estilo; más podrá ser considerado noticia blanda (Reinemann et al., 2011, p. 13).

La anterior definición se apoya en tres dimensiones. La primera es la "dimensión temática" y se refiere a la relevancia política. Bruns y Marcinowski (1997) entienden el grado de relevancia política como un indicador de la medida en que el contenido de un ítem noticioso se refiere a normas, objetivos, intereses y actividades relacionadas con la preparación, afirmación e implementación de decisiones políticas vinculantes referidas a conflictos sociales. A su vez, la medición de la relevancia política de un ítem noticioso puede realizarse a través de cuatro indicadores empíricos: la mención de actores sociales, de autoridades vinculadas con los procesos de toma de decisión, de un plan o programa propuesto, y de las personas preocupadas por esa decisión (Reinemann et al., 2011, p. 13). El sentido de la relación estipulada es: a más indicadores presentes, más alto el grado de relevancia política 
de un ítem noticioso. Los autores entienden que en esta primera dimensión o "dimensión temática”, el ablandamiento de una noticia podría significar la reducción de su grado de relevancia política. Una segunda dimensión es la "frame o marco". Los autores creen que se debe distinguir entre las informaciones que enfatizan la relevancia o consecuencia pública de un evento, y las noticias que se enmarcan en los aspectos o consecuencias personales o privados. En esta segunda dimensión, el ablandamiento de las noticias estaría indicado por un frame que se centra en cuestiones privadas o personales, o en eventos aislados o ejemplares. Finalmente, la tercera dimensión sobre la cual se asienta la definición es la de "el estilo". Permite diferenciar entre noticias que incluyen manifestaciones explícitas de las interpretaciones, opiniones e impresiones personales del periodista, y las que no incluyen esas perspectivas personales. El ablandamiento de las noticias en esta dimensión sería indicativo de un estilo más personal o emocional.

En el caso de nuestro trabajo, utilizamos dos de esas dimensiones para clasificar la variable 'tipo de información comunicada'. A una la denominamos "información dura-propiamente política-pública”, y a la otra "información blanda-privada-infotainment”. Siguiendo con la misma estipulación que realizamos en un trabajo anterior (García-Beaudoux, Berrocal \& D’Adamo, 2020), la primera de ellas se encuentra presente cuando las publicaciones se refieren a eventos, normas, objetivos, intereses o actividades relacionados con la preparación, afirmación o implementación de decisiones políticas. La segunda, cuando las publicaciones se caracterizan por el predominio de contenido de entretenimiento sobre el informativo.

\section{2. ¿Por qué Instagram?}

En 2020, el 49\% de la población del mundo utiliza redes sociales e Instagram es una red en expansión (Galeano, 2020). A finales de 2017, dicha plataforma contaba con más de 800 millones de seguidores y se producían aproximadamente 300 millones de publicaciones diarias (Instagram, 2017; Kemp, 2018). En 2018, el 76\% de la población argentina ya se encontraba activa en redes sociales y de las ocho horas diarias que dedicaba a navegar por Internet, más de tres de ellas se destinaban a las redes sociales, siendo Instagram la que conseguía mayor crecimiento (Kemp, 2018). En 2020, Facebook era la red social que continuaba liderando, con 2.449 millones de usuarios en el mundo. Instagram le seguía, posicionada en el segundo lugar, con 1.000 millones, 200 millones de usuarios más de los que tenía en 2019 (Galeano, 2020). En tanto plataforma visual y dada su tasa de crecimiento, 
Instagram abre una nueva posibilidad para continuar explorando la clase de información que se comunica durante las campañas electorales.

Instagram es una plataforma que se ha adoptado para la producción y distribución de mensajes políticos, cifrados principalmente en códigos de imágenes de foto y video. Si bien su uso se ha profesionalizado, su naturaleza visual y móvil genera en la ciudadanía la ilusión de una comunicación política más espontánea, que combina vida pública y privada (Selva \& Caro, 2017). López y Domenéch (2018) indican que la profesionalización del uso de la imagen política en las redes sociales responde, entre otros factores, a que les facilita a los candidatos presentarse de manera efectiva mezclando elementos de su vida personal y profesional, y también a que las imágenes son herramientas poderosas para capturar la atención y persuadir. Los partidos políticos y sus candidatos tienden con frecuencia a optar por un estilo de comunicación política personalizada, que incluye aspectos de la vida privada y que recurre a conocidas tácticas como la visualización, la simplificación y la polarización (Meyen, Thieroff \& Strenger, 2014). En Instagram se publican mensajes simples en forma de fotos, álbumes, selfies, videos y collages, que persiguen la conexión emocional con la ciudadanía, humanizando a líderes y candidatos protagonistas en autopresentaciones en las que se destacan sus atributos personales y sus competencias, en mensajes naturales, cercanos y espontáneos que generan ilusión de intimidad (Ekman \& Widholm, 2017).

Aun cuando el uso de Instagram en la arena política se encuentra en una fase experimental e inicial o, en el mejor de los casos intermedia, se la considera una plataforma con capacidad de mejorar el intercambio con los votantes, movilizarlos, recaudar fondos, instalar ciertas agendas y tendencias, así como de potenciar la construcción de liderazgo a través de la personalización de los líderes (Towner \& Muñoz, 2017; García-Beaudoux, Berrocal \& D’Adamo, 2020). De ahí la importancia de estudiarla en el contexto de una campaña electoral.

Por otro lado, cabe especificar que en Instagram la imagen fotográfica ocupa un lugar central. En efecto, en la muestra total de los y las candidatos del último mes de la campaña de 2019, el $36 \%$ de las publicaciones contiene una foto y el $38 \%$ más de una (ver tabla 1), predominancia que también se observa en la muestra específica de la candidata y los candidatos del Frente de Todos: del total de sus publicaciones, un $42 \%$ contiene una imagen fotográfica y el $19 \%$ más de una (ver tabla 3). 
Si se revisan los estudios de la fotografía en Instagram debemos recalcar que uno de los autores pioneros en este estudio es Manovich (2017), quien analiza imágenes actuales de internautas de distintas ciudades del mundo y acuña el término "instagramismo" para dar cuenta de la identidad cultural contemporánea que favorece la forma y explica que con Instagram se pueden crear perfiles únicos a través de las fotografías.

En el caso de los y las políticas las fotografías pueden ilustrar un acontecimiento público o uno del orden de lo privado e íntimo que acerque al político a un rasgo de lo mundano, en línea con la política contemporánea. En el caso de la "selfie política", en otro lugar (Slimovich, 2020) hemos mostrado que aparece de modo fragmentario y esporádico en las redes de los políticos y políticas porque "pone en juego una enunciación individual/extrainstitucional (p. 197) y "tensiona la distancia entre la enunciación del asesor y la del político que ha caracterizado los discursos de los políticos en las redes sociales desde sus inicios en la segunda década de este siglo" (p.186).

El uso de Facebook y Twitter en las últimas campañas políticas argentinas ha sido ampliamente estudiado (Annunziata, Ariza \& March, 2018; D’Adamo, García-Beaudoux \& Kievsky, 2015; García-Beaudoux, Gavensky \& D’Adamo 2018; Gindin, 2018; Slimovich, 2012, 2014, 2017, 2018a, 2018b; Ventura, 2018). En los últimos años ha crecido exponencialmente el uso de Instagram tanto por parte de los internautas ciudadanos como de los políticos y políticas. En este punto nos preguntamos: ¿cómo son los discursos políticos argentinos contemporáneos en Instagram en el período previo a las elecciones de 2019? ¿Qué tipo de información predomina en sus feed?

\section{Método y muestra}

La investigación constó de dos etapas. En la primera, se realizó una primera aproximación de carácter exploratorio en la que se analizaron las publicaciones que realizaron en Instagram durante la campaña electoral de 32 candidatas y candidatos que participaron de las elecciones de octubre de 2019 en Argentina. En la segunda, se empleó una metodología de análisis del discurso y sociosemiótica (Metz, 1974; Verón, 1987, 2013; Scolari, 2008, 2020; Steimberg, 1993; Fernández, 1994, 2018; Carlón, 2004, 2016) y el análisis se concentró en comparar los discursos políticos de 3 de esos candidatos en sus feed de Instagram. 


\subsection{Etapa 1: Exploración de las publicaciones efectuadas por 32 candidatas y candidatos durante el mes previo a las elecciones de octubre de 2019 en Argentina}

En una primera etapa, se realizó un estudio empírico de carácter exploratorio, con alcance descriptivo y de secuencia temporal transversal. Se utilizó el método de análisis de contenido cuantitativo, que produce datos nominales o frecuencias que cuentan la ocurrencia de determinado tipo de contenido (Krippendorff, 1990; Neuendorff, 2002; Igartua, 2006), por ser el que mejor se ajusta al objeto de estudio seleccionado. La selección de las variables y el establecimiento de los indicadores incluidos en el diseño de la investigación se deriva de una extensiva revisión bibliográfica, y de categorías creadas y utilizadas por los autores en investigaciones similares anteriores (García-Beaudoux \& D'Adamo, 2016a, 2016b, 2016c, 2013, 2017; García-Beaudoux, D’Adamo \& Zubieta, 2016; D’Adamo, García-Beaudoux \& Kievsky, 2015) que asimismo han sido citadas y utilizadas por otros investigadores (Quevedo \& Portalés, 2017; López \& Doménech, 2018). Con la finalidad de aumentar la confiabilidad, se utilizaron categorías excluyentes y descriptivas que requirieran bajo nivel de inferencia por parte de los codificadores.

La muestra está conformada por un total de 1505 unidades. Las unidades de análisis son las publicaciones de Instagram efectuadas por los 32 candidatos que obtuvieron la mayor cantidad de votos en las PASO (elecciones Primarias Abiertas y Obligatorias) en los tres distritos electorales más grandes de Argentina (Provincia de Buenos Aires, Provincia de Córdoba y Provincia de Santa Fe). Eso los habilitó para competir por cargos de elección popular para la presidencia de la nación, gobernaciones provinciales y cargos legislativos para el Congreso Nacional en las elecciones que tuvieron lugar en Argentina en octubre de 2019. Se analizan todas las publicaciones que realizaron (fotografías, videos, álbumes y sus respectivos textos) en sus feed de Instagram, en el período comprendido durante los 30 días previos a la fecha en que tuvieron lugar las elecciones (ver tabla 1). 
Tabla 1. Características de muestra y de las unidades de análisis

\begin{tabular}{l|l|l} 
Tipo de unidad de análisis & $\begin{array}{l}\text { N total de unidades de } \\
\text { análisis }=1505\end{array}$ & $\mathbf{\%}$ \\
\hline Foto / imagen & 544 & $36 \%$ \\
Video & 391 & $26 \%$ \\
Álbum & 570 & $38 \%$ \\
Total & 1.505 & $100 \%$
\end{tabular}

Fuente: Elaboración propia

Las publicaciones que conforman la muestra analizada en la primera etapa de la investigación, corresponden a las y los candidatos de los tres distritos electorales más grandes de Argentina a los siguientes cargos ejecutivos y legislativos: presidencia de la nación (cargo ejecutivo nacional), vicepresidencia de la nación, gobernación provincial (cargo ejecutivo provincial), vicegobernación provincial y candidaturas del primer y segundo lugar de cada una de las tres listas más votadas para congresistas nacionales (cargo legislativo nacional) en cada uno de los tres distritos. En la tabla 2 se observa el detalle de las candidaturas seleccionadas para el análisis de sus publicaciones en Instagram.

Tabla 2. Muestra de candidatos y candidatas en Instagram

\begin{tabular}{|c|c|c|c|c|c|}
\hline $\begin{array}{l}\text { Nombre del } \\
\text { candidato/ } \\
\text { a }\end{array}$ & Usuario & $\begin{array}{l}\text { Cantidad de } \\
\text { seguidores }\end{array}$ & $\begin{array}{l}\text { Unidad } \\
\text { de } \\
\text { análisis } \\
\text { totales } \\
\text { (videos } \\
\text { y fotos) } \\
\text { N total } \\
=1505\end{array}$ & $\begin{array}{l}\text { Período } \\
\text { analiza } \\
\text { do }\end{array}$ & $\begin{array}{l}\text { Tipo de } \\
\text { candidatura } \\
\text { (presidencia, } \\
\text { vicepresiden } \\
\text { cia, } \\
\text { gobernación } \\
\text { provincial, } \\
\text { congresista } \\
\text { nacional) }\end{array}$ \\
\hline $\begin{array}{l}\text { 1.Mauricio } \\
\text { Macri } \\
\text { (Juntos por el } \\
\text { Cambio) }\end{array}$ & $\begin{array}{l}@ \text { mauriciomac } \\
\text { ri }\end{array}$ & $1,1 \mathrm{M}$ & 171 & $\begin{array}{l}\text { Del } 27 \text { de } \\
\text { septiemb } \\
\text { re a } 27 \text { de } \\
\text { octubre }\end{array}$ & Presidencia \\
\hline
\end{tabular}




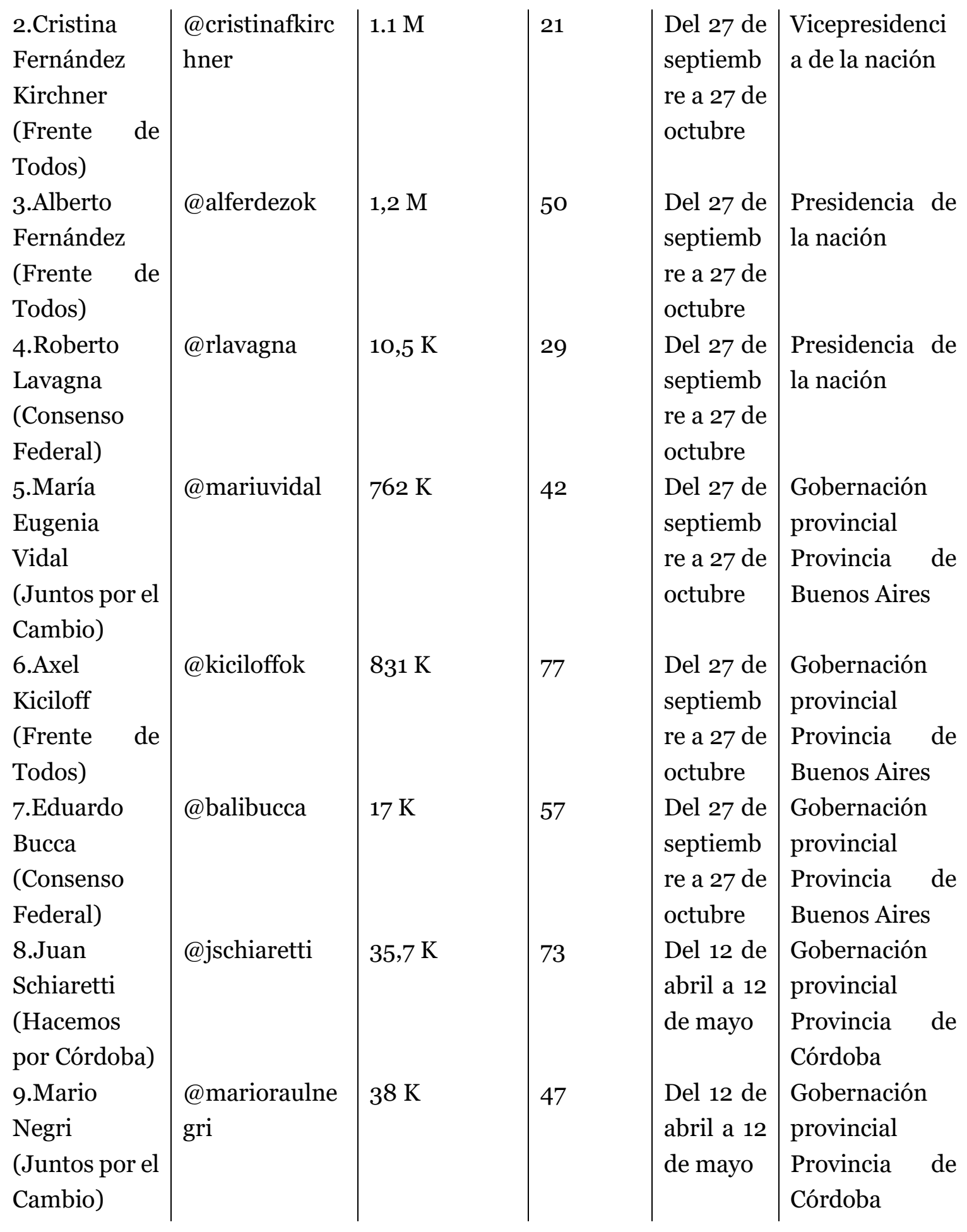




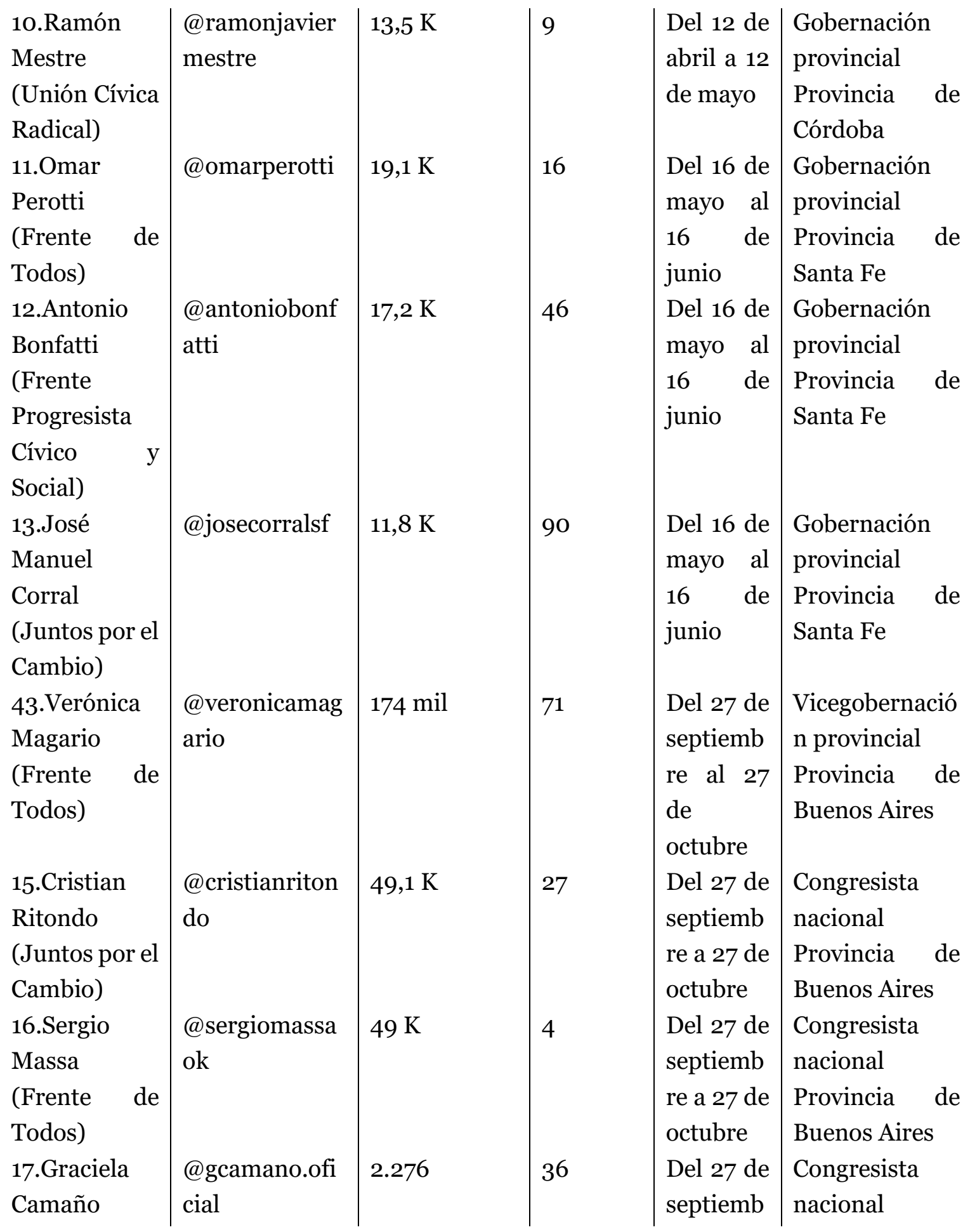




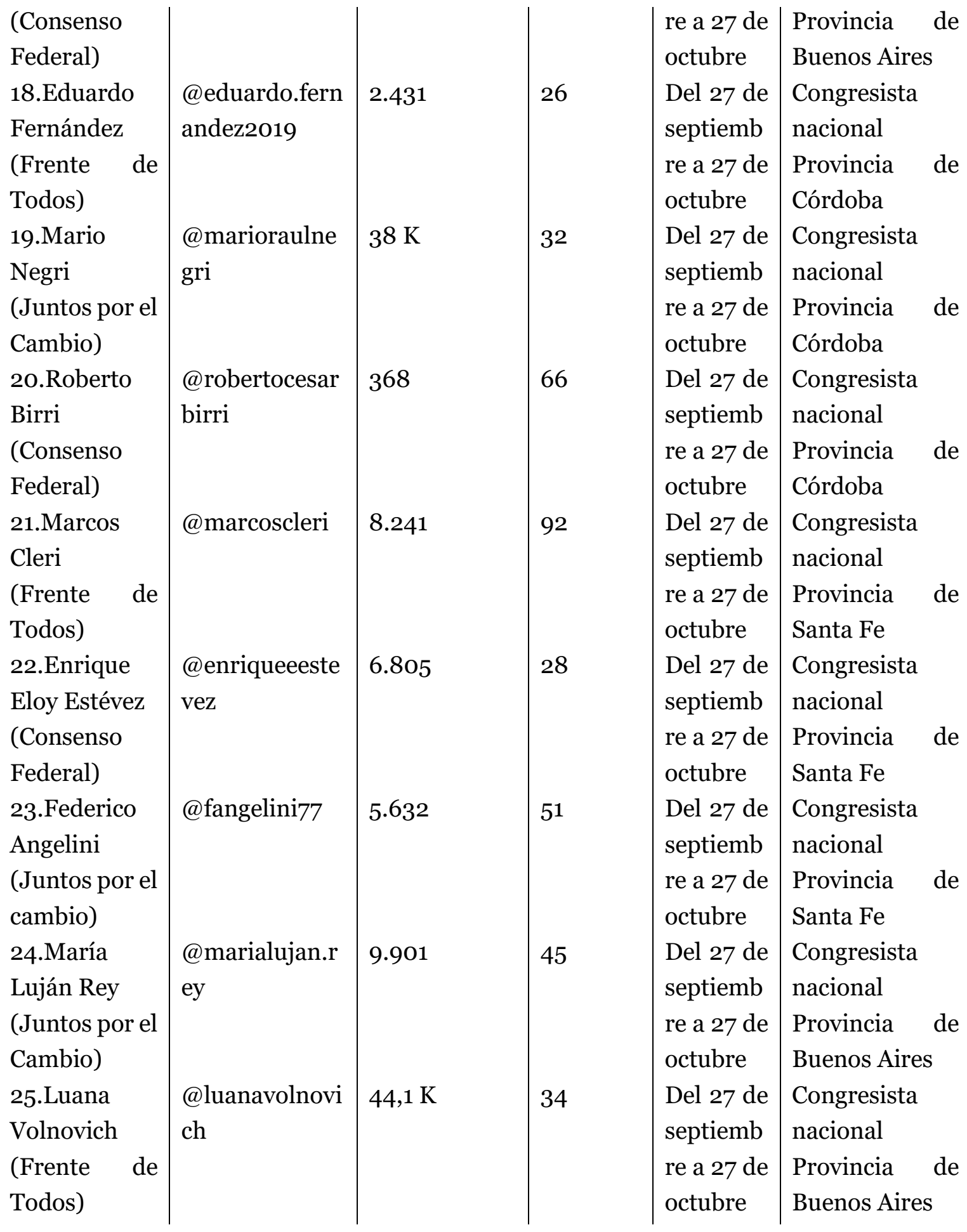




\begin{tabular}{|c|c|c|c|c|c|}
\hline \\
\hline 26.Alejandro & @topo_arg & 384 & $\mathrm{O}$ & Del $27 \mathrm{de}$ & Congresista \\
\hline Rodríguez & & & & septiemb & nacional \\
\hline (Consenso & & & & re a $27 \mathrm{de}$ & Provincia de \\
\hline Federal) & & & & octubre & Buenos Aires \\
\hline 27.Gabriela & $@$ gabiestevezo & $14,2 \mathrm{~K}$ & 32 & Del $27 \mathrm{de}$ & Congresista \\
\hline Estévez & $\mathrm{k}$ & & & septiemb & nacional \\
\hline (Frente de & & & & re a $27 \mathrm{de}$ & Provincia \\
\hline Todos) & & & & octubre & Córdoba \\
\hline 28.Soher El & $@$ @soherelsukar & 2.792 & 44 & Del 27 de & Congresista \\
\hline Sukaria & & & & septiemb & nacional \\
\hline (Juntos por el & & & & re a $27 \mathrm{de}$ & Provincia de \\
\hline Cambio) & & & & octubre & Córdoba \\
\hline 29.Betiana & @betianacabre & 1.785 & 12 & Del $27 \mathrm{de}$ & Congresista \\
\hline Cabrera & raf & & & septiemb & nacional \\
\hline Fasolis & & & & re a $27 \mathrm{de}$ & Provincia de \\
\hline (Consenso & & & & octubre & Córdoba \\
\hline Federal)) & & & & & \\
\hline 30.Alejandra & @alejandraobe & 2.616 & 87 & Del 27 de & Congresista \\
\hline Del Huerto & & & & septiemb & nacional \\
\hline Obeid & & & & re a $27 \mathrm{de}$ & Provincia de \\
\hline (Frente de & & & & octubre & Santa Fe \\
\hline Todos) & & & & & \\
\hline 31.Carolina & $@$ piedrabuena & 2.115 & 32 & Del 27 de & Congresista \\
\hline Piedrabuena & carolina & & & septiemb & nacional \\
\hline (Consenso & & & & re a $27 \mathrm{de}$ & Provincia de \\
\hline Federal) & & & & octubre & Santa Fe \\
\hline 32.Ximena & $@$ ximegarciab & 2.728 & 58 & Del $27 \mathrm{de}$ & Congresista \\
\hline García & & & & septiemb & nacional \\
\hline (Juntos por el & & & & re a $27 \mathrm{de}$ & Provincia de \\
\hline Cambio) & & & & octubre & Santa Fe \\
\hline
\end{tabular}

Para el registro y la medición de contenidos se diseñó un protocolo de codificación que fue sometido a una prueba piloto, en la que participaron los tres codificadores que efectuaron la medición definitiva. Con referencia a la fiabilidad del análisis, se siguió el modelo de Lemish 
y Tidhar (1999), una fórmula basada en el consenso entre los codificadores para elegir una única entrada o categoría para cada variable. En las situaciones en que los codificadores no alcanzaron un acuerdo, se siguió el procedimiento de Garramone, Steele y Pinkleton (1991) y el desacuerdo fue resuelto eligiendo la codificación seleccionada por dos de los tres.

La variable analizada fue el tipo de información comunicada. Se estipularon dos dimensiones para dicha variable: "información propiamente política o dura", e "infoentretenimiento o información blanda". Asimismo, los investigadores estipulamos las definiciones conceptuales para cada una de las dimensiones y, luego, establecimos indicadores para el registro y la medición empírica:

1. Información propiamente política (información dura):

- Definición conceptual: publicaciones referidas a temas, eventos, normas, objetivos, intereses o actividades relacionados con la preparación, afirmación o implementación de decisiones políticas.

- Definición operacional: mención de actores sociales, de autoridades vinculadas con los procesos de toma de decisión, referencias a un plan o programa propuesto y/o a las personas preocupadas por esa decisión. El marco o frame utilizado hace énfasis en la relevancia y/o consecuencia pública de la información que se presenta.

2. Politainment (información blanda):

- Definición conceptual: infoentretenimiento político, predominio de contenido de entretenimiento sobre el informativo.

- Definición operacional: presencia de personas del ámbito político en espacios no específicamente políticos o informativos, presencia de información política blanda y entretenida en las publicaciones, tendencia a la personalización y a concentrar el protagonismo en los candidatos. El marco o frame utilizado hace énfasis en aspectos privados o personales. Se prioriza el contenido anecdótico, emotivo y humano sobre los contenidos políticos, cívicos o públicos.

\subsection{Etapa 2: Tres candidatos y candidatas del Frente de Todos}

En la segunda etapa, de la muestra general de 32 candidatos y candidatas anteriormente mencionados, diferenciamos a tres: dos candidatos y una candidata. Seleccionamos a los 
integrantes de la fórmula ganadora presidencial, conformada por Alberto Fernández y Cristina Fernández de Kirchner, y al ganador del distrito electoral más grande de la Argentina: Axel Kicillof. De este modo, realizamos una indagación específica de estos tres candidatos y de la candidata del Frente de Todos, quienes resultaron ganadores en tres cargos ejecutivos de la mayor relevancia: la presidencia y vicepresidencia de la nación, y la gobernación de la provincia de Buenos Aires que constituye el principal distrito electoral de la Argentina. El objetivo fue analizar si sus publicaciones reflejaban las tendencias generales identificada en la etapa 1 de la investigación o si, por el contrario, mostraban diferencias.

Para el análisis de los candidatos del Frente de Todos se emplea una metodología de análisis del discurso y sociosemiótica (Metz, 1974; Verón, 1987, 2013; Scolari, 2008, 2020; Steimberg, 1993; Fernández, 1994, 2018; Carlón, 2004, 2016), a través de una investigación comparativa. En este sentido, el análisis se concentra en comparar los discursos políticos de ellos tres en sus feed de Instagram, en el último mes de campaña, teniendo en cuenta también la materia significante (Metz, 1974): foto/video/álbum de fotos (ver tabla 3). Estos resultados se contrastan, a su vez, con la muestra total.

Se concibe a los discursos como configuraciones espaciotemporales de sentido, que tienen un anclaje social y que poseen restricciones en su generación y en su lectura (Verón, 1987). Se realizó un análisis de los motivos temáticos y temas (Segre, 1985) que se desprenden de las publicaciones en Instagram durante el último mes de campaña de 2019. En relación con los rasgos temáticos, enfocamos en las "acciones o situación según esquemas de representabilidad históricamente elaborados y relacionados, previos al texto" (Steimberg, 1993, p. 44). Nos orientamos tanto a las unidades más pequeñas, los motivos temáticos; como a las de carácter más macro (los temas); teniendo en cuenta que ambas atraviesan los distintos textos y son por lo tanto anteriores y exteriores al propio texto de análisis (Segre, 1985). De este modo, distinguimos entre motivos del orden de lo público (actos de campaña, encuentro con figuras públicas internacionales, entre otros) y aquellos del orden de lo privado (encuentro con su familia, descripción de estado de ánimo, entre otros). A los motivos temáticos recurrentes referentes a lo público se los ligará a la información propiamente política (información dura) y a los referentes a lo privado se los ligará a la politainment (información blanda)

En el caso de los tres candidatos y candidata del Frente de Todos se aplicó también una clasificación de las publicaciones que se realizó en estudios anteriores (Slimovich, 2017, 
2018b), que distingue -además del tipo de motivo temático recurrente- si aparecen "microargumentaciones lógicas” y “micro-argumentaciones pasionales” (Slimovich, 2012, p. 152) (ver tabla 4). Nos referimos a argumentaciones breves, condensadas de sentido en las cuales convergen diferentes medios y redes sociales (ibídem). Las micro-argumentaciones lógicas son los "micro-entimemas y micro-ejemplos" que se desarrollan en las redes sociales y las "micro-argumentaciones pasionales" son aquellas también propias de los espacios digitales que implican argumentaciones breves vinculadas al pathos aristotélico y que apelan a producir emociones por la vía argumentativa.

Tabla 3. Características de las publicaciones de dos candidatos y una candidata del Frente de Todos

\begin{tabular}{|l|l|l|}
\hline Tipo de unidad de análisis & $\begin{array}{l}\text { N total de unidades de } \\
\text { análisis }=\end{array}$ \\
\hline Foto / imagen & 60 & $42 \%$ \\
\hline Video & 55 & $39 \%$ \\
\hline Álbum & 27 & $19 \%$ \\
\hline Total & 142 & $100 \%$ \\
\hline
\end{tabular}

Fuente: Elaboración propia

La variable y sus dimensiones fueron convertidos en los siguientes indicadores que conforman la matriz de codificación que se ha utilizado para la clasificación de las unidades de análisis que componen la muestra (tabla 4). En la tabla 5 se registraron los indicadores que formaron parte de la clasificación que se aplicó exclusivamente a los candidatos y la candidata del Frente de Todos. 
Tabla 4. Matriz de clasificación

\section{Variables: Tipo de información comunicada}

II. Dimensiones de la variable

\subsection{Información Propiamente política}

1.2.. Politainment

\begin{tabular}{|c|c|}
\hline $\begin{array}{l}\text { I.I. Indicadores de } \\
\text { información propiamente } \\
\text { política }\end{array}$ & $\begin{array}{l}\text { I.II. Indicadores } \\
\text { politainment }\end{array}$ \\
\hline $\begin{array}{l}\text { 1. Publicaciones de actualidad } \\
\text { política } \\
\text { 2. Comunicación de propuestas } \\
\text { 3. Imágenes en debates políticos } \\
\text { 4. Presencia en programas } \\
\text { especializados en contenidos } \\
\text { políticos o informativos } \\
\text { 5. Imágenes de la actividad } \\
\text { política y actos de campaña } \\
\text { 6. Imágenes con otros dirigentes } \\
\text { políticos } \\
\text { 7. Petición de apoyo y/o de voto } \\
\text { 8. Otras }\end{array}$ & $\begin{array}{l}\text { 1. Publicaciones que muestran al } \\
\text { candidato o candidata como una } \\
\text { mujer u hombre común. } \\
\text { Humanización del candidato/a } \\
\text { 2. Imágenes en programas de TV } \\
\text { de entretenimiento } \\
\text { infoentretenimiento } \\
\text { 3. Imágenes con sus familias / vida } \\
\text { privada / amigos personales } \\
\text { 4. Imágenes en situaciones } \\
\text { informales con sus equipos de } \\
\text { trabajo } \\
\text { 5. Humor } \\
6 \text { Otras }\end{array}$ \\
\hline
\end{tabular}

Fuente: Elaboración propia 
Tabla 5. Matriz de clasificación para les candidates del Frente de Todos

\section{Variables: Tipo de información comunicad}

\begin{tabular}{ll|cr}
\hline $\begin{array}{l}\text { I.I. Indicadores de motivos } \\
\text { temáticos vinculados a lo público } \\
\text { /(información dura) }\end{array}$ & $\begin{array}{l}\text { I.II. Indicadores de motivos } \\
\text { temáticos vinculados lo } \\
\text { privado }\end{array}$ \\
(información \\
blanda)
\end{tabular}

Fuente: Elaboración propia

\section{Resultados}

El $90 \%$ de la información publicada en Instagram por la muestra de 32 candidatos y candidatas analizada, corresponde a información propiamente política, información dura. Por el contrario, sólo el 9 \% de las publicaciones corresponden a politainment o información blanda (ver tabla 6). La tendencia a la predominancia por la información dura, se reitera al analizar las publicaciones de la muestra seleccionada de los 3 candidatos y candidata del Frente de Todos, siendo incluso más marcada la predominancia: el $99 \%$ de los contenidos refieren a motivos del orden de lo público (información dura) y sólo el 1 \% corresponden a motivos ligados al orden de lo privado (información blanda) (ver tabla 7). 
Tabla 6. Tipo de información política comunicada en los 32 candidatas y candidatos en el mes previo a las elecciones de 2019 en Instagram

Fuente: Elaboración propia

\begin{tabular}{l|l}
$\begin{array}{l}\text { Tipo de información } \\
\text { política comunicada }\end{array}$ & $\begin{array}{l}\text { Resultados total } \\
\text { muestra }\end{array}$ \\
\hline $\begin{array}{l}\text { Información propiamente } \\
\text { política (info dura) }\end{array}$ & $90,4 \%$ \\
\hline Politainment (info blanda) & $9,6 \%$
\end{tabular}

Tabla 7. Tipo de información política comunicada en las cuentas de Instagram de Cristina Fernández de Kirchner, Alberto Fernández y Axel Kicillof, en el mes previo a las elecciones de 2019

\begin{tabular}{l|l} 
Tipo de información & Resultados total \\
política comunicada & muestra \\
\hline $\begin{array}{l}\text { Información propiamente } \\
\text { política (vinculado a lo } \\
\text { público) (info dura) }\end{array}$ & $99,30 \%$ \\
\hline $\begin{array}{l}\text { Información vinculada a lo } \\
\text { privado/íntimo (info } \\
\text { blanda) }\end{array}$ & $0,70 \%$ \\
\end{tabular}

Fuente: Elaboración propia

Del total de publicaciones de la muestra de 32 candidatos y candidatas en Instagram en el mes previo a la elección general de 2019, analizamos las características de las 10 publicaciones con más likes. En este punto, cabe observar que las publicaciones que generaron más reacciones positivas entre los internautas fueron las que contenían información propiamente política (el 83,5 \%) versus el 16, 5 \% de las publicaciones con contenido de politainment (ver tabla 8) Se evidencia así una cierta preferencia por aquellas publicaciones que posicionan enunciativamente a los políticos y políticas en su rol público y cierta indiferencia por las publicaciones que contienen retazos de lo íntimo u operaciones de “teatralización de la vida privada" (Slimovich, 2012, p. 145). 
Tabla 8. Características del conjunto de las diez publicaciones de cada candidato que obtuvieron más likes

\begin{tabular}{ll|l}
$\begin{array}{l}\text { Las 10 publicaciones con } \\
\text { más likes de cada } \\
\text { candidato/a }\end{array}$ & $\begin{array}{l}\text { Resultados } \\
\text { total } \\
\text { muestra }\end{array}$ \\
\hline $\begin{array}{l}\text { Publicaciones con información } \\
\text { propiamente política (info dura) }\end{array}$ & $83,5 \%$ \\
\hline $\begin{array}{l}\text { Publicaciones con politainment } \\
\text { (info blanda) }\end{array}$ & $16,5 \%$ \\
\hline
\end{tabular}

Fuente: Elaboración propia

En la tabla 9 se puede observar que en relación con las publicaciones de Instagram que contenían información propiamente política, se halló que la mayor cantidad refieren a "imágenes en actividad política y actos de campaña" (el 35, 5 \%). En segundo lugar, se encuentran las publicaciones que hacen alusión a la "actualidad política" (26,2 \%) y, en tercer lugar, el 16,3\%, corresponde a "imágenes de las y los candidatos con otros dirigentes políticos”. En menor proporción se registra la comunicación de propuestas $(9,5 \%)$ y la petición directa de apoyo o voto $(9,4 \%)$. Las categorías que contienen menor cantidad de publicaciones en el último mes de campaña son "imágenes en debates políticos" e "imágenes participando en medios de comunicación especializados en contenidos políticos o informativos" ambas con el $1 \%$ de las publicaciones. 
Tabla 9. Características de las publicaciones de información propiamente política

\begin{tabular}{l|l}
$\begin{array}{l}\text { Características de la información } \\
\text { propiamente política publicada (info } \\
\text { dura) }\end{array}$ & $\begin{array}{l}\text { Resultados } \\
\text { muestra }\end{array}$ \\
\hline $\begin{array}{l}\text { Actualidad política } \\
\text { Comunicación de propuestas }\end{array}$ & $26,2 \%$ \\
Imágenes en debates políticos & $9,5 \%$ \\
Imágenes participando en medios de & $1,0 \%$ \\
comunicación especializados en contenidos & $1,0 \%$ \\
políticos o informativos & \\
Imágenes en actividad política y actos de & $35,5 \%$ \\
campaña & \\
Imágenes de las y los candidatos con otros & $16,3 \%$ \\
dirigentes políticos & \\
Petición de apoyo y/o del voto & $9,4 \%$ \\
Otras & $1,1 \%$
\end{tabular}

Fuente: Elaboración propia

Con relación a las publicaciones de Instagram que contenían politainment, se registró que la mayor cantidad de publicaciones (33, 7\%) corresponde a "mujer/hombre común, humanización del candidato/a". En segundo lugar, se halló la categoría "con sus familias/vida privada/amigos personales" (28,9\%). Asimismo, también se registraron "las y los candidatos en situaciones informales con sus equipos de trabajo" $(15,8)$ y otras con el $15 \%$. Por último, el 6,6 \% de las publicaciones contenían humor (ver tabla 10). 
Tabla 10. Características de las publicaciones de politainment

\begin{tabular}{l|l}
$\begin{array}{l}\text { Características de Politainment } \\
\text { (info blanda) }\end{array}$ & $\begin{array}{l}\text { Resultados } \\
\text { Candidatas }\end{array}$ \\
\hline $\begin{array}{l}\text { Mujer/hombre común, humanización } \\
\text { del candidato/a }\end{array}$ & $33,7 \%$ \\
$\begin{array}{l}\text { Imágenes participando en programas } \\
\text { de televisión e entretenimiento o }\end{array}$ & -- \\
infoentretenimiento & \\
Con sus familias / vida privada / & $\mathbf{2 8 , 9 \%}$ \\
amigos personales & \\
Las y los candidatos en situaciones \\
informales con sus equipos de trabajo \\
$\begin{array}{l}\text { Humor } \\
\text { Otras }\end{array}$ & $\mathbf{1 5 , 8 \%}$ \\
\end{tabular}

Fuente: Elaboración propia

Si nos centramos en los candidatos y candidata del Frente de Todos, se observa que se replica la segmentación entre información propiamente política e información vinculada a lo privado que registramos de modo global. Si nos enfocamos en las 10 publicaciones con más likes de los 3 candidatos también se registra la repetición de la tendencia general que indicaba que las publicaciones que generan mayor cantidad de reacciones positivas son las que responden a información propiamente política. En efecto, el 96,7 \% de las publicaciones con más likes corresponde a información dura y el sólo el 3,33 \% a información blanda (ver tabla 11). En este punto cabe observar que tanto cuando se observa de manera general a todos los candidatos y candidatas como cuando observamos a la fórmula ganadora presidencial y al ganador del distrito electoral más importante del país, en todos los casos, se registra que los políticos y políticas optan por la predominancia de información propiamente política en su feed de Instagram. 
Tabla 11. Tipo de información política comunicada en las 10 publicaciones con más likes de Instagram de Cristina Fernández de Kirchner, Alberto Fernández y Axel Kicillof, en el mes previo a las elecciones generales de 2019

\begin{tabular}{l|l} 
Tipo de información política & Resultados \\
comunicada en los 10 con más likes de & \\
cada candidato & \\
\hline $\begin{array}{l}\text { Información propiamente política (vinculado } \\
\text { a lo público) (info dura) }\end{array}$ & $96,70 \%$ \\
$\begin{array}{l}\text { Información vinculada a lo privado (info } \\
\text { blanda) }\end{array}$ & $3,33 \%$ \\
\end{tabular}

Fuente: Elaboración propia

Si se desagregan las categorías para cada candidato del Frente de Todos, se observa que, en el caso de Cristina Fernández de Kirchner, dentro de las 10 publicaciones con mayor cantidad de megusteos, predominan las que contienen motivos temáticos vinculados a actos de campaña (30 \%). En segundo lugar, las "micro-argumentaciones" contra el adversario electoral y las publicaciones que contienen motivos temáticos vinculados al acto de cierre de campaña (ambas con el $20 \%$ ). Por último, el $10 \%$ corresponde a la presentación del libro Sinceramente, los contenidos vinculados a lo específicamente electoral y la categoría "recuerdos de Néstor Kirchner" armada para aunar las publicaciones que contienen motivos temáticos que recuerdan a Néstor Kirchner en el aniversario de su fallecimiento (ver tabla 12). 
Tabla 12. Tipo de información política comunicada en las 10 publicaciones con más likes de Instagram de Cristina Fernández de Kirchner en el mes previo a las elecciones generales de 2019

\begin{tabular}{l|l}
$\begin{array}{l}\text { Las 1o publicaciones con más likes de } \\
\text { CFK, según el tipo de contenido }\end{array}$ & $\begin{array}{l}\text { Resultados sobre } \\
\text { videos y } 5 \text { fotos }\end{array}$ \\
\hline Presentación de libro & $10 \%$ \\
Acto de campaña & $30 \%$ \\
Acto de cierre de campaña & $20 \%$ \\
Contenidos vinculados a lo específicamente & $10 \%$ \\
electoral & \\
Recuerdos de Néstor Kirchner & $10 \%$ \\
"Micro-argumentación" contra adversario & $20 \%$ \\
electoral &
\end{tabular}

Fuente: Elaboración propia

En el caso de las 10 publicaciones con más likes de Alberto Fernández, se observa que la "referencia a líderes internacionales-el encuentro con líderes internacionales" ocupa el primer lugar (30 \% de las publicaciones). Las otras publicaciones que más generan reacciones positivas son las que contienen "micro-argumentaciones lógicas" contra su adversario electoral (20 \%). En efecto, se trata de publicaciones que en Instagram a partir de la combinación texto- imagen fotográfica o texto-video condensan sentidos y configuran una "micro-argumentación multimediática" (Slimovich, 2012, p. 152) que apunta a probar el fracaso de la gestión de Cambiemos en el país. Por último, el 10 \% de las publicaciones que generaron más likes corresponden a la categoría: "acto de campaña", "acto de cierre de campaña”, contenidos vinculados a los específicamente electoral y se repite también la categoría: "recuerdos de Néstor Kirchner" (ver tabla 13). 
Tabla 13. Tipo de información política comunicada en las 10 publicaciones con más likes de Instagram de Alberto Fernández en el mes previo a las elecciones generales de 2019

\begin{tabular}{|c|c|}
\hline $\begin{array}{l}\text { Las } 10 \text { publicaciones con más likes de } \\
\text { Alberto Fernández, según el tipo de } \\
\text { contenido }\end{array}$ & $\begin{array}{l}\text { Resultados sobre } \\
\text { videos y } 5 \text { fotos }\end{array}$ \\
\hline Referencia & $30 \%$ \\
\hline $\begin{array}{l}\text { internacionales/Encuentros con líderes } \\
\text { internacionales }\end{array}$ & \\
\hline Acto de campaña & $10 \%$ \\
\hline Acto de cierre de campaña & $10 \%$ \\
\hline $\begin{array}{l}\text { Contenidos vinculados a lo específicamente } \\
\text { electoral }\end{array}$ & $10 \%$ \\
\hline Recuerdos de Néstor Kirchner & $10 \%$ \\
\hline $\begin{array}{l}\text { "Micro-argumentación" lógica contra } \\
\text { adversario electoral }\end{array}$ & $20 \%$ \\
\hline $\begin{array}{l}\text { Salida con miembro de su familia o mascota } \\
\text { Elaboración propia }\end{array}$ & $10 \%$ \\
\hline
\end{tabular}

Fuente: Elaboración propia

En la tabla 14 se observan las publicaciones con más likes del feed de Axel Kicillof en el mes previo a las elecciones generales de 2019. Se registra que la mayor cantidad de reacciones positivas estuvo conformada por la categoría: "acto de campaña” que en el caso del gobernador de la provincia de Buenos Aires se articuló con la caravana en la provincia de Buenos Aires, realizada en un modesto automóvil Renault Clio. En efecto, el 6o \% de las publicaciones con más likes corresponde a esta categoría. En segundo lugar, se ubica la categoría: "acto de cierre de campaña", categoría que también aparece entre las que genera mayores reacciones positivas en Alberto Fernández y Cristina Fernández de Kirchner. Por último, el 10 \% de las publicaciones con mayor cantidad de likes corresponde a "contenidos vinculados a lo específicamente electoral”. 
Tabla 14. Tipo de información política comunicada en las 10 publicaciones con más likes de Instagram de Axel Kicillof en el mes previo a las elecciones generales de 2019

\begin{tabular}{l|l} 
Las 1o publicaciones con más likes de & $\begin{array}{l}\text { Resultados sobre } 5 \\
\text { vxel Kicillof, según el tipo de contenido y fotos }\end{array}$ \\
\hline Acto de campaña/Caravana de campaña & $60 \%$ \\
Acto de cierre de campaña & $30 \%$ \\
Contenidos vinculados a lo específicamente & $10 \%$ \\
electoral &
\end{tabular}

Fuente: Elaboración propia (AS)

\section{Conclusiones}

Una de las cuestiones que se desprende del análisis realizado es la posibilidad de reformular las categorías y dimensiones de análisis a partir de los resultados obtenidos. Nos referimos específicamente a la tradicional separación entre información blanda e información dura como tipos de clasificación excluyentes. La observación se genera a partir de las publicaciones de la muestra analizada que refieren a motivos temáticos vinculados con los recuerdos a Néstor Kirchner. Tanto Cristina Fernández de Kirchner como Alberto Fernández publicaron fotos de Néstor Kirchner en sus feed de Instagram, que combinaban con el texto lingüístico, en ocasión del aniversario de su fallecimiento (ver imagen 1 e imagen 2). En ambos casos, esas publicaciones fueron las que generaron la mayor cantidad de reacciones positivas. 
Imagen 1. Publicación realizada por los 9 años del fallecimiento del expresidente Néstor Kirchner.

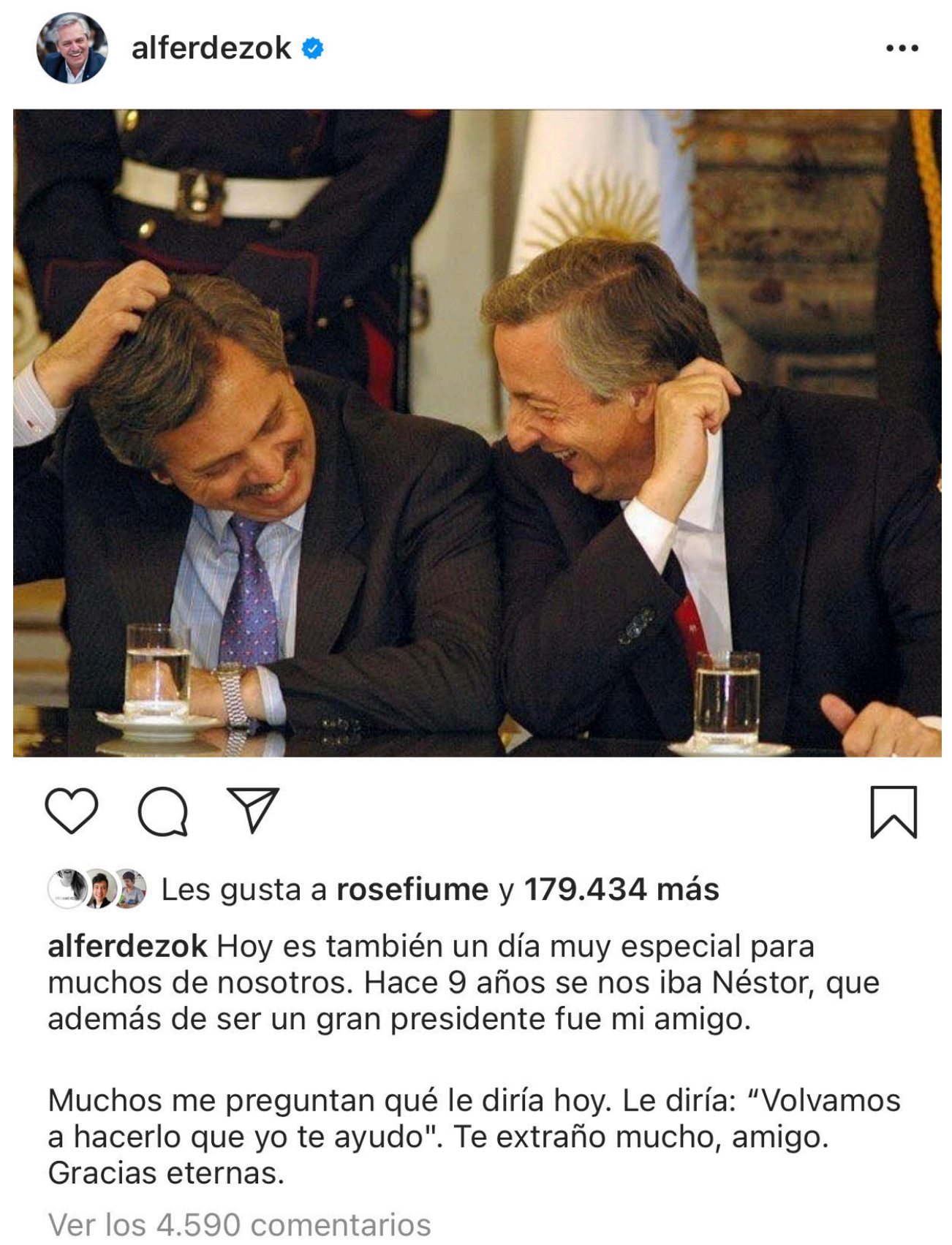

Fuente: publicación en el feed de Alberto Fernández el 27 de octubre de 2019. 
Imagen 2. Publicación realizada por los 9 años del fallecimiento del expresidente Néstor Kirchner.

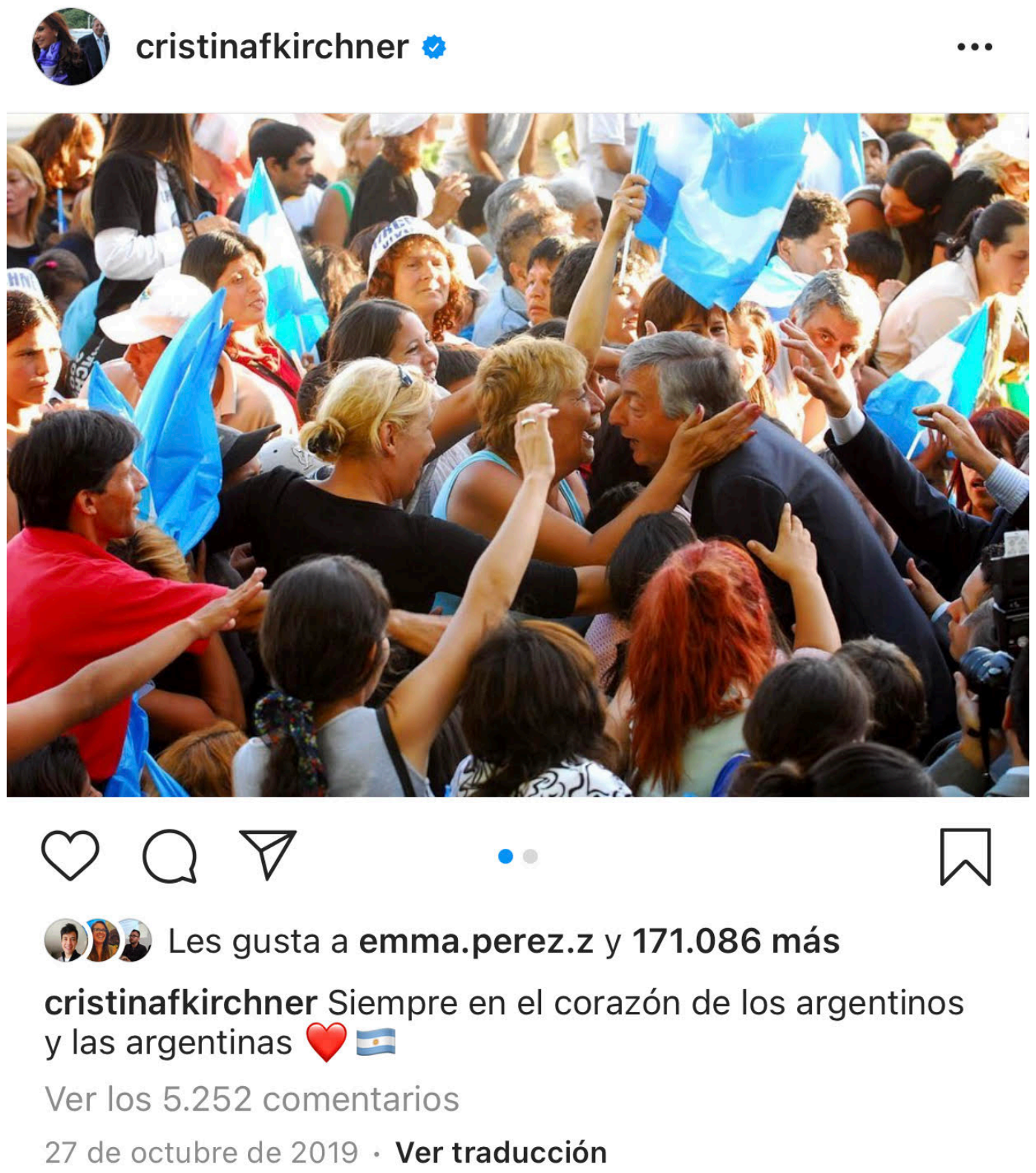

Fuente: publicación en el feed de Cristina Fernández de Kirchner el 27 de octubre de 2019 
A los fines analíticos, en esta investigación las publicaciones de la categoría "recuerdos de Néstor Kirchner" fueron clasificadas en la dimensión "información propiamente política", dado que hacen referencia a Néstor Kirchner en su calidad de expresidente de Argentina y dirigente peronista. No obstante, junto con su contenido duro y explícitamente político, las publicaciones apelaban a despertar las emociones de los internautas. En efecto, la publicación de Alberto Fernández alude a la relación personal que tenía con Néstor Kirchner (el hecho de que fueran amigos) y en el caso de la de Cristina Fernández se apela a rememorar la relación que estableció el expresidente y dirigente político con sus seguidores.

$\mathrm{Al}$ revisitar las categorías pensadas para diferenciar el tipo de noticia, se observa que este tipo de publicaciones tensiona la clasificación. Por un lado, no se puede asociar a la categoría de "noticia dura" (Curran et al., 2009) dado que no hay en esas publicaciones en Instagram estrictamente información sobre política, y tampoco se trata de "noticias blandas" dado que no refiere a celebridades sino a políticos, si bien los aborda desde el interés humano.

A nuestro criterio, la categoría "recuerdos de Néstor Kirchner" se sitúa así en un espacio híbrido entre la información "dura" y la información "blanda" puesto que si bien hace mención a un actor político que participa en la toma de decisión - lo que definimos como "información propiamente política"; también pone en primer plano la personalización, concentra el protagonismo en Néstor Kirchner y prioriza el contenido humano por sobre lo público-lo que definimos como "politainment"-. No se dispone en la actualidad de una categoría específica para incluir este tipo de contenidos que refieren a la vida pública y a la vez apelan a suscitar emociones. En definitiva, esta superposición entre la dimensión de contenido duro y propiamente político con la dimensión informativa de contenido blando y emocional es indicativa de la necesidad de continuar explorando las matrices y categorías de clasificación generadas para estudiar este tipo de fenómenos de comunicación política.

\section{Conflicto de interés}

Las autoras declaran que no existe conflicto de interés. 


\section{Referencias bibliográficas}

ANNUNZIATA, R., ARIZA, A. \& MARCH, V. (2018): “Gobernar es estar cerca”. Las estrategias de proximidad en el uso de las redes sociales de Mauricio Macri y María Eugenia Vidal. Revista mexicana de opinión pública, (24), pp. 71-93. https://dx.doi.org/10.22201/fcpys.24484911e.2018.24.61520

BRUNS, T. \& MARCINOWSKI, F. (1997): Politische Information im Fernsehen: Eine Längsschnittstudie zur Veránderung der Politikvermittlung in Nachritchen uns politischen Informationssendugen. Opalden, Leske + Bludrich.

CARLÓN, M. (2004). Sobre lo televisivo. Dispositivos, discursos y sujetos. Buenos Aires, La Crujía.

(2016): Apropiación contemporánea de la teoría comunicacional de Eliseo Verón. En E. Vizer y C. Vidales (Coords.), Comunicación, campo(s) teorías y problemas. Una perspectiva Internacional (pp. 125-153). Barcelona, Editorial Comunicación Social.

CASTELLS, M. (2009): Comunicación y poder. Madrid, Alianza Editorial.

CHERESKY, I. (Comp.) (2006): La política después de los partidos. Buenos Aires, Prometeo.

CURRAN, J., IYENGAR, S., LUNDA, A. B. \& SALOVAARA-MORING, I. (2009): Media system, public knowledge and democracy: A comparative Study. European Journal of Communication, 24(1), pp. 5-26. https://doi.org/10.1177/0267323108098943

D’ADAMO, O., GARCÍA-BEAUDOUX, V. \& KIEVSKY, T. (2015): Comunicación política y redes sociales. Análisis para las campañas y las elecciones legislativas de 2013 en la ciudad de Buenos Aire. Revista Mexicana de Opinión Pública, 19, pp. 107-125.

D’ADAMO, O. \& GARCÍA-BEAUDOUX, V. (2013): Arquitectura del relato político. Storytelling al servicio de la comunicación política. En I. Crespo y J. del Rey (Eds.), Comunicación Política y Campañas Electorales en América Latina (pp. 55-68). Buenos Aires, Biblos. 
EKMAN, M. Y. \& WIDHOLM, A. (2017): Political Communication in an Age of Visual Connectivity: Exploring Instagram Practices among Swedish Politicians. Northern lights: Film \& media studies yearbook, 15(1), pp. 15-32. https://doi.org/10.1386/nl.15.1.15 1

FERNÁNDEZ, J. L. (1994): Los lenguajes de la radio. Buenos Aires, Atuel.

(2018): “Comprender las plataformas mediáticas”. En M. Maestri, Plataformas mediáticas. Elementos de análisis y diseño de nuevas experiencias (pp. 29-62). Buenos Aires, La Crujía.

FERNÁNDEZ, M. (2014): Sobre la mediatización. Revisión conceptual y propuesta analítica. La Trama de la Comunicación, 18, pp. 189-209.

GALEANO, S. (2020): Cuáles son las redes sociales con más usuarios del mundo (2021). Marketing4ecommerce. $\quad$ https://marketing4ecommerce.net/cuales-redes-sociales-conmas-usuarios-mundo-ranking/

GARCÍA-BEAUDOUX, V. \& D’ADAMO, O. (2016a): Campaña negativa. Análisis de los spots televisivos de siete elecciones presidenciales argentinas (1983-2011). En J. del Rey Morató, A. B. Campillo y Y. Guan (Eds.), Campañas electorales en América Latina, España y Portugal. Madrid, Fragua.

(2016b): Spot y Storytelling. El anuncio televisivo y la narración de historias al servicio de la comunicación política. En O. Leyva (Coord.), El spot político en América Latina (pp. 289-314). Guadalajara, Universidad de Guadalajara.

(2016c): Spots electorales y publicidad política. En J. Santiago, M. G. Ortega y J. A. Carpio (Coords.), Consultoría política (Cap. 20, pp. 473-494). Madrid, Ed. Amarante.

(2013): Propuesta de una matriz de codificación para el análisis de las campañas negativas. Revista OPERA, 13, pp. 7-23.

(2017): ¿Ideología, imágenes, temas o partidos? Las claves de los anuncios televisivos de las elecciones presidenciales argentinas 2007, 2011 y 2015. En I. Crespo y M. Belinchón 
(Eds.), ¿Compiten las ideas? La presencia de la ideología en las campañas electorales modernas de Latinoamérica y España (cap. 1, pp. 15-34). Valencia, Tirant Lo Blanch.

GARCÍA-BEAUDOUX, V., BERROCAL, S. \& D'ADAMO, O. (2020): Atributos de liderazgo en Instagram durante las elecciones presidenciales en Argentina 2019. Index comunicación, 10(1), pp. 173-194.

GARCÍA-BEAUDOUX, V., D’ADAMO, O. \& SLAVINSKY, G. (2005): Comunicación Política y Campañas Electorales. Barcelona, GEDISA.

GARCÍA-BEAUDOUX, V., D’ADAMO, O. \& ZUBIETA, E. (2016): Presidente ideal y comunicación política. Expectativas de los ciudadanos e imágenes proyectadas en los spots de las campañas presidenciales argentinas 2003, 2007 y 2011. Revista Marco, 2, pp. 1-23.

GARCÍA-BEAUDOUX, V., GAVENSKY, M. \& D’ADAMO, O. (2018): ¿Qué información comparten candidatas y candidatos en Internet para conectar con los votantes? Más Poder Local, (36), pp. 37-41.

GARRAMONE, G. M., STEELE, M. E. \& PINKLETON, B. (1991): The Role of Cognitive Schemata in Determining Candidate characteristics effects. En F. Biocca (Ed.), Television and Political Advertising, 1. Psychological Processes (pp. 311-328). Hillsdale, Erlbaum.

GINDIN, I. L. (2018): “Sorry. ¿Sabés qué?”: proximidad y ethos íntimo en @CFKArgentina. Icono 14, 16(1), pp. 114-135. DOI: 10.7195/ri14.v16i1.1117

HJARVARD, S. (2008): The mediatization of Society. A Theory of the Media as Agents of Social and Cultural Change. Nordicom Review, 29 (2), pp. 105-134. http://www.nordicom.gu.se/sites/default/files/kapitel-pdf/269 hjarvard.pdf (2014): A midiatizacao da cultura e da sociedad. San Leopoldo, Editora Unisinos.

IGARTUA, J. J. (2006): Métodos cuantitativos de investigación en comunicación. Barcelona, Bosch. 
INSTAGRAM (2017): Instagram's 2017 Year in Review. www.Instagram-press.com, Nov. 29.

KEMP, S. (2018): Digital in 2018: World's internet users pass the 4 billion mark. WeAreSocial. https://wearesocial.com/blog/2018/o1/global-digital-report-2018

KRIPPENDORFF, K. (1990): Metodología del análisis de contenido. Barcelona, Paidós Comunicación.

LEHMAN-WILZIG, S. \& SELETZKY, M. (2010): Hard news, soft news, 'general'news: The necessity and utility of an intermediate classification. Journalism, 11(1), pp. 37-56.

LEMISH, D. \& TIDHAR, C. E. (1999): Still Marginal: Women in Israel's Television Election Campaign. Sex roles: A Journal of Research, 41, pp. 389-412.

LÓPEZ, P. \& DOMÉNECH, H. (2018): Instagram y la espectacularización de las crisis políticas. Las $5 \mathrm{~W}$ de la imagen digital en el proceso independentista de Cataluña. El profesional de la información, 27(5), pp. 1013-1029.

MANIN, B. (1998): Los principios del gobierno representativo. Madrid, Alianza.

MANOVICH, L. (2017): Instagram and contemporary image. Manovich.net. http://manovich.net/index.php/projects/instagram-and-contemporary-image

MAZZOLENI, G. \& SCHULZ, W. (1999): "Mediatization" of Politics: A challenge for Democracy? Political Communication, 16(3), pp. 247-261.

METZ, C. (1974): El estudio semiológico del lenguaje cinematográfico, Revista Lenguajes 1(2). Buenos Aires, Nueva Visión.

MEYEN, M., THIEROFF, M. \& STRENGER, S. (2014): Mass Media Logic and the Mediatization of Politics: A Theoretical Framework. Journalism studies, 15(3), pp. 271 - 288. https://doi.org/10.1080/1461670X.2014.889459

NEUENDORFF, K. A. (2002): The content analysis guidebook. Cleveland, Sage Publishing. 
PATTERSON, T. E. (2000): Doing Well and Doing Good: How Soft News and Critical Journalism are Shrinking the News Audience and Weakening Democracy-and What news Outlets can do About It. Cambridge, MA: Harvard University, John F. Kennedy School of Government

QUEVEDO, R. \& PORTALÉS, M. (2017): Imagen y comunicación política en Instagram. Celebrificación de los candidatos a la presidencia del Gobierno. El profesional de la información, 2(5), pp. 916-927. https://doi.org/10.3145/epi.2017.sep.13

REINEMANN, C., STANYER, J., SCHERR, S. \& LEGNANTE, G. (2011): Hard and Soft News: A Review of Concepts, Operationalizations and Key Findings. Journalism, 13(2), pp. 1-19.

SCOLARI, C. (2008): Hipermediaciones. Elementos para una teoría de la Comunicación Digital Interactiva. Barcelona, Gedisa.

(Ed.) (2020): “Competencias transmedia y estrategias de aprendizaje informal” y "Medios y plataformas". En C. Scolari (Ed.), Adolescentes, medios de comunicación y culturas colaborativas. Aprovechando las competencias transmedia de los jóvenes en el aula (pp. 26-113). Barcelona, Universitat Pompeu Fabra.

SEGRE, C. (1985): Tema / motivo. En C. Segre, Principios de análisis del texto literario. Barcelona, Editorial Crítica.

SELVA, D. \& CARO, L. (2017): Uso de Instagram como medio de comunicación política por parte de los diputados españoles: la estrategia de humanización en la 'vieja' y la 'nueva' política'. El profesional de la información, 26(5), pp. 903-915. https://doi.org/10.3145/epi.2017.sep.12

SLIMOVICH, A. (2012): El Facebook de los gobernantes. El caso de Cristina Fernández de Kirchner y de Mauricio Macri. En M. Carlón y A. Fausto Neto (Comps.), Las políticas de los internautas. Nuevas formas de participación (pp. 137-154). Buenos Aires, La Crujía. 
(2014): El discurso macrista en Twitter: un análisis sobre la campaña para la reelección del jefe de gobierno de Buenos Aires. Revista de Estudios Políticos y Estratégicos, II(1).

http://vtte.utem.cl/wpcontent/themes/blogum/revista epe/o3 Rev estudios politicos estrategicos vol2 n1 2014 Ana S Discurso Macrista 8-27.pdf

(2016): La interfaz entre lo político y lo informativo en la mediatización televisiva y las redes sociales en las campañas argentinas de 2009 y 2011 [Tesis doctoral, Facultad de Ciencias Sociales de la Universidad de Buenos Aires, Buenos Aires].

(2017): La ruta digital a la presidencia argentina. Un análisis político e hipermediático de los discursos de Mauricio Macri en las redes sociales. Dixit, (26), pp. 24-43. https://revistas.ucu.edu.uy/index.php/revistadixit/article/view/1321/1369

(2018a): \#TinelliMercenarioK. La mediatización del Presidente argentino y los trolls macristas. InMediaciones de la Comunicación, 13(1), pp. 159-186.

https://revistas.ort.edu.uy/inmediaciones-de-la-comunicacion/article/view/2830/2823

(2018b). El macrismo y la oposición kirchnerista en las redes sociales en la campaña electoral de 2017. Revista Científica Electrónica de la Red de Carreras de Comunicación Social y Periodismo de la Argentina, 6, pp. 6-31.

http://perio.unlp.edu.ar/ojs/index.php/revcom/article/view/4898

(2020): Instagram y política. Mediatización y circulación en los perfiles de Cristina Fernández de Kirchner y Mauricio Macri. En M. Mendoza, M. Dagatti y P. C. López-López (Coords.), Cuadernos del Centro de Estudios en Diseño y Comunicación No. 112, Imagen e identidad política en América Latina.

https://fido.palermo.edu/servicios dyc/publicacionesdc/archivos/840 libro.pdf

STEIMBERG, O. (1993): Semiótica de los medios masivos. Buenos Airesl, Atuel.

STRÖMBÄCK, J. \& ESSER, F. (2014): Introduction: Making Sense of the Mediatization of Politics. Journalism Studies, 15(3), pp. 243-255. 
STRÖMB̈̈CK, J. (2008): Four Phases of Mediatization: An Analysis of the Mediatization of Politics. International Journal of Press/Politics, 13(3), pp. 228-246.

http://hij.sagepub.com/content/13/3/228.short?rss=1\&ssource $=\mathrm{mfr}$

TOWNER, T. L. \& MUÑOS, C. L. (2017): Picture Perfect? The Role of Instagram in Issue Agenda Setting during the 2016 Presidential Primary Campaign. Social science computer review, 36(4), pp. 484-499. https://doi.org/10.1177/0894439317728222

TUCHUMAN, G. (1972): Objectivity as a Strategic Ritual. American Journal of Sociology, 77, pp. 660-679.

(1973): Making news by doing work: Routinizing the unexpected. The American Journal of Sociology, 79(1), pp. 387-402.

VENTURA, A. (2018): Cuestión de imagen: análisis de los mensajes de Twitter de los candidatos presidenciales argentinos durante el debate previo al ballotage 2015. Prágmática Socio Cultural 6(1), pp. 1-32. https://philpapers.org/rec/VENCDI-2

VERÓN, E. (1987): La semiosis social. Barcelona: Gedisa.

(1998 [1995]): Mediatización de lo político. Estrategias, actores y construcción de los colectivos. En G. Gauthier, A. Gosselin y J. Mouchon (Comps.), Comunicación y Política (pp. 220-236). Barcelona, Gedisa.

(2001 [1984]). El cuerpo de las imágenes. Buenos Aires, Argentina: Norma.

(2013): La semiosis social, 2. Ideas, momentos, interpretantes. Buenos Aires, Paidós. 